\title{
Labour and carbon
}

Environ. Sociol. http://doi.org/cx2j (2018)

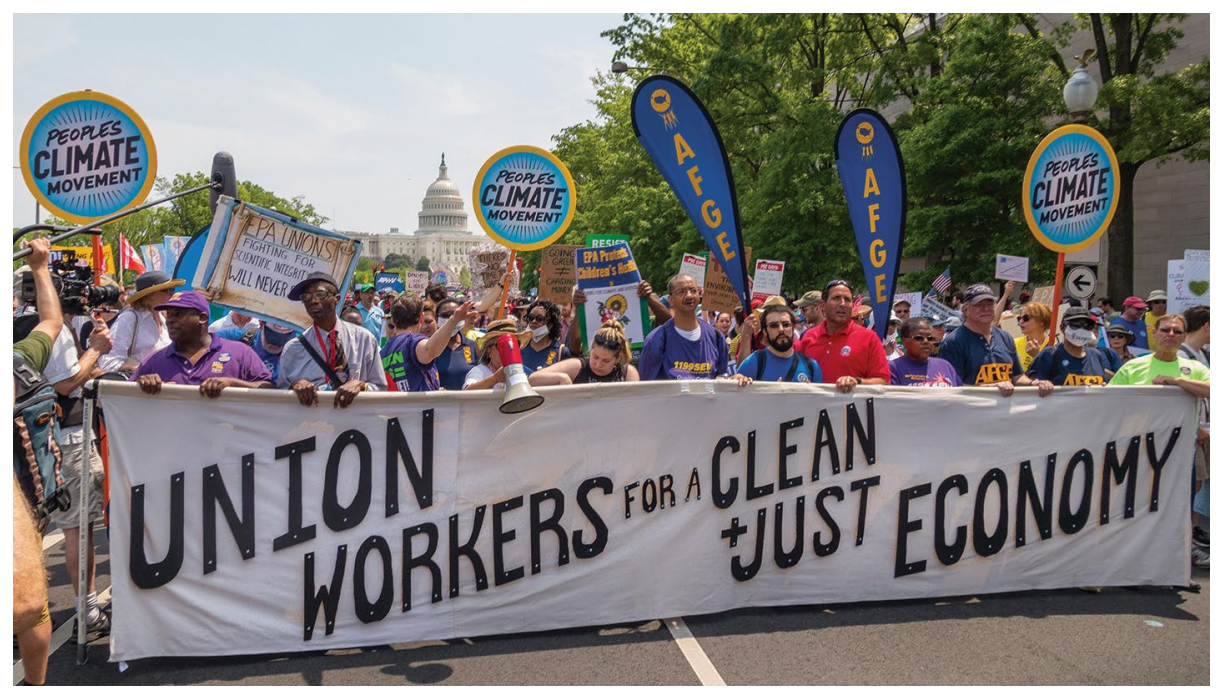

Credit: ROB CRANDALL / ALAMY STOCK PHOTO

The interaction of labour unions with environmental issues has sometimes been framed within the paradigm of the 'treadmill of production', which posits that due to the relentless pace of economic activity demanded by a modern global economy, workers and their organizations also have a vested interest in keeping employment and wages high even at the potential expense of the environment.

However, according to Allen Hyde at Georgia Tech and Todd Vachon at Rutgers, the presence and strength of labour unions may actually help mitigate environmental impacts as measured through greenhouse gas emissions. Looking at 18 of the most industrialized countries between 1990 and
2010, the authors hypothesized and found that union density in a country is associated with reduced emissions, such that every $1 \%$ increase in union density correlates to an emissions decline of approximately $0.349 \%$ (in the absence of other interactive effects such as employment protection laws or participation in government). Such results suggest that labour unions may be rejecting the framing of jobs or the environment and that the labour governance of a country can help to determine its climate policy.

\section{Ryan Scarrow}

Published online: 10 January 2019

https://doi.org/10.1038/s41893-018-0215-9 